\title{
THE NOVEMBER MEETING IN PRINCETON
}

The four hundred nineteenth meeting of the American Mathematical Society was held at Princeton University on Saturday, November 2 , in connection with the year-long celebration of Princeton's Bicentennial. The attendance was approximately two hundred fifty, including the following two hundred nineteen members of the Society:

Milton Abramowitz, C. R. Adams, C. B. Allendoerfer, R. L. Anderson, T. W. Anderson, R. F. Arens, Emil Artin, R. P. Bailey, Joshua Barlaz, A. F. Bartholomay, P. T. Bateman, G. E. Bates, E. G. Begle, Richard Bellman, Stefan Bergman, Lipman Bers, J. H. Bigelow, Archie Blake, R. P. Boas, G. L. Bolton, T. A. Botts, A. T. Brauer, Paul Brock, A. B. Brown, R. C. Buck, G. E. Bullock, R. S. Burington, Hobart Bushey, J. H. Bushey, S. S. Cairns, W. B. Campbell, F. L. Celauro, Claude Chevalley, K. L. Chung, Alonzo Church, Randolph Church, Edmund Churchill, A. H. Clifford, R. F. Clippinger, I. S. Cohen, Richard Courant, V. F. Cowling, D. R. Crosby, H. B. Curry, J. H. Curtiss, J. F. Daly, M. D. Darkow, D. R. Davis, John DeCicco, L. S. Dederick, D. B. DeLury, C. H. Denbow, C. H. Dowker, Y. N. Dowker, T. L. Downs, Arnold Dresden, Nelson Dunford, W. D. Duthie, Jacques Dutka, Churchill Eisenhart, L. P. Eisenhart, Benjamin Epstein, Paul Erdös, Ky Fan, Herbert Federer, J. M. Feld, William Feller, N. J. Fine, W. B. Fite, Edward Fleisher, M. M. Flood, R. H. Fox, Hilda Geiringer, Abe Gelbart, J. H. Giese, B. P. Gill, H. E. Goheen, V. D. Gokhale, H. H. Goldstine, A. W. Goodman, W. H. Gottschalk, E. J. Gumbel, Theodore Hailperin, N. A. Hall, R. W. Hamming, O. G. Harrold, K. E. Hazard, L. A. Henkin, Einar Hille, A. P. Hillman, Banesh Hoffman, T. R. Hollcroft, E. M. Hull, L. C. Hutchinson, J. A. Jenkins, Bjarni Jónsson, Aida Kalish, Irving Kaplansky, Edward Kasner, M. E. Kellar, D. E. Kibbey, J. R. Kline, E. R. Kolchin, M. Z. Krzywoblocki, Jack Laderman, J. W. Lasley, Solomon Lefschetz, Joseph Lehner, Marguerite Lehr, R. A. Leibler, Howard Levi, Norman Levinson, Charles Loewner, E. R. Lorch, A. N. Lowan, N. H. McCoy, A. W. McMillan, Brockway McMillan, L. A. MacColl, Saunders MacLane, M. H. Martin, W. T. Martin, Imanuel Marx, A. E. Meder, A. N. Milgram, Don Mittleman, Deane Montgomery, Vladimir Morkovin, Richard Morris, Marston Morse, C. A. Nelson, David Nelson, E. D. Nering, O. E. Neugebauer, A. V. Newton, P. B. Norman, Nilan Norris, Lawrence Norwood, C. O. Oakley, E. R. Ott, J. C. Oxtoby, J. S. Oxtoby, L. G. Peck, A. M. Peiser, W. H. Pell, Anna Pell-Wheeler, A. J. Penico, B. J. Pettis, C. R. Phelps, R. S. Phillips, Everett Pitcher, F. V. Pohle, Harry Polachek, Walter Prenowitz, Hans Rademacher, L. L. Rauch, G. E. Raynor, Mina Rees, F. D. Rigby, John Riordan, E. K. Ritter, H. P. Robertson, M. S. Robertson, J. B. Robinson, R. M. Robinson, S. L. Robbinson, P. C. Rosenbloom, Raphael Salem, Pierre Samuel, Arthur Sard, S. A. Schaaf, A. T. Schafer, R. D. Schafer, I. J. Schoenberg, Pincus Schub, Abraham Schwartz, I. E. Segal, C. E. Shannon, H. N. Shapiro, Max Shiffman, James Singer, L. L. Smail, V. E. Spencer, N. E. Steenrod, R. R. Stoll, E. G. Straus, L. M. Straus, M. M. Sullivan, C. C. Torrance, M. M. Torrey, H. I. Treiber, C. A. Truesdell, A. W. Tucker, Bryant Tuckerman, J. W. Tukey, H. S. Vandiver, H. E. Vansant, Oswald Veblen, D. F. Votaw, G. L. Walker, A. D. Wallace, R. M. Walter, J. B. Walton, W. R. Wasow, G. C. Webber, F. J. Weyl, Hermann Weyl, A. L. Whiteman, P. M. Whitman, D. V. Widder, A. S. Wightman, S. S. Wilks, C. S. Williams, Clement Winston, Y. C. Wong, Bertram Yood, J. W. Young, Leo Zippin, Antoni Zygmund. 
On Saturday morning there were two sections, one for papers in Algebra and Topology in which Professor N. E. Steenrod presided, and one for papers in Analysis, Geometry and Applied Mathematics, in which Professors Einar Hille and D. V. Widder presided.

The general session on Saturday afternoon, Professor W. B. Fite presiding, opened with a welcome by Dr. H. S. Taylor, Dean of the Graduate School, Princeton University. On behalf of the Society, Professor N. H. McCoy presented an expression of appreciation to Princeton University and the Committee on Arrangements and congratulations to Princeton University on its Bicentennial. Professor J. H. C. Whitehead of the University of Oxford gave an address on Combinatorial homotopy theory.

Members of the Society were guests of the Institute for Advanced Study at tea from 4-6 P.M.

Under the auspices of Princeton University, an informal discussion of the current state of mathematics throughout the world was held at 7:45 P.M., Professor Einar Hille presiding. The speakers and their topics were as follows: Professor Harald Cramér, on mathematics in the Scandinavian countries and the recent Scandinavian Mathematical Congress; Professor Claude Chevalley on mathematics in France during and since the war; Professor Solomon Lefschetz on mathematics in the U.S.S.R. and, more briefly, in Italy and China; Professor H. P. Robertson on mathematics and science in Europe, especially in Germany during and since the war; Professor Marston Morse on a Mathematical Congress, open to mathematicians of all nations, probably to be held in the U.S.A. in a few years. A discussion period followed during which Professor Arnold Dresden described a plan sponsored by the American Mathematical Society to assist in building up the mathematical libraries of Europe and Asia.

Titles and cross references to the abstracts of the papers read follow below. Papers whose abstract numbers are followed by the letter $t$ were read by title. Papers numbered 1-9 were presented in the section for Algebra and Topology, papers 10-18 in the section for Analysis, Geometry and Applied Mathematics, papers 19-49 were presented by title. Paper 15 was read by Professor Kasner, and paper 18 by Mr. Harry Polachek. Mr. Roberts was introduced by Professor C. C. Lin.

1. Nilan Norris: An extension of an equality among averages. (Abstract 52-11-396.)

2. E. R. Kolchin: Algebraic matric groups and the Picard-Vessiot theory of homogeneous linear ordinary differential equations. (Abstract 52-11-349. 
3. P. M. Whitman: Finite groups with a cyclic group as lattice-homomorph. (Abstract 52-11-355.)

4. A. T. Brauer: Limits for the characteristic roots of a matrix. II. (Abstract 52-11-347.)

5. R. M. Robinson: Unsymmetrical approximation of irrational numbers. (Abstract 52-11-351.)

6. Everett Pitcher: Critical point inequalities for a nondegenerate functional. (Abstract 52-11-405.)

7. R. H. Fox: On a problem of S. Ulam concerning Cartesian products. (Abstract 52-11-401.)

8. Ky Fan: On partially ordered additive groups of continuous functions. (Abstract 52-11-400.)

9. C. H. Dowker: An extension of Alexandroff's mapping theorem. (Abstract 52-11-398.)

10. R. C. Buck: On some properties of arithmetic density. Preliminary report. (Abstract 52-11-361.)

11. V. F. Cowling: On the form of certain entire functions. (Abstract 52-11-363.)

12. M. Z. Krzywoblocki: A local maximum property of the fourth coefficient of schlicht functions. (Abstract 52-11-369.)

13. P. C. Rosenbloom: Entire associative functions. (Abstract 52-11373.)

14. Walter Prenowitz: Characterization of the lattice of convex sets of a descriptive geometry. (Abstract 52-11-391.)

15. Edward Kasner and John DeCicco: Geometry of harmonic transformations. (Abstract 52-9-322.)

16. S. A. Schaaf: A cylinder cooling problem. (Abstract 52-11-385.)

17. H. E. Goheen: $A$ bound for the error in computing the Bessel functions of the first kind by recurrence. (Abstract 52-11-380.)

18. Harry Polachek and R. J. Seeger: On the existence of solutions for three-shock Prandtl-Meyer configurations in the case of weak reflected shocks. (Abstract 52-11-381.)

19. Warren Ambrose: Direct sum theorem for Haar measures. (Abstract 52-11-356-t.)

20. R. F. Arens: Location of spectra in Banach*-algebras. (Abstract 52-11-357-t.)

21. Lipman Bers: $A$ property of bounded analytic functions. (Abstract 52-11-358-t.)

22. Lipman Bers: On rings of analytic functions. (Abstract 52-11359-t.)

23. H. W. Brinkmann: On the prime divisors of a polynomial with 
integral coefficients. (Abstract 52-11-348-t.)

24. J. P. Brown: Cyclic characteristic curves of a system of differential equations. (Abstract 52-9-286-t.)

25. R. C. Buck: Interpolation series. (Abstract 52-11-360-t.)

26. Herman Chernoff: $A$ note on the inversion of power series. (Abstract 52-11-378-t.)

27. John DeCicco: Constrained motion upon a surface under a generalized field of force. (Abstract 52-11-388-t.)

28. C. L. Dolph: Nonlinear integral equations of the Hammerstein type. (Abstract 52-11-364-t.)

29. S. T. Hu: On extension of homotopy. (Abstract 52-11-402-t.)

30. R. C. James: Inner products in normed linear spaces. (Abstract 52-11-368-t.)

31. E. R. Kolchin: Extensions of differential fields. III. (Abstract 52-11-350-t.)

32. G. W. Mackey: On the domains of closed linear transformations in Hilbert space. Preliminary report. (Abstract 52-11-370-t.)

33. Deane Montgomery: A theorem on locally euclidean groups. (Abstract 52-11-403-t.)

34. A. P. Morse: Perfect blankets. (Abstract 52-11-371-t.)

35. S. B. Myers: Banach spaces of continuous functions. (Abstract 52-11-404-t.)

36. Everett Pitcher: Exact homomorphism sequences for a nest of three spaces. (Abstract 52-11-406-t.)

37. E. L. Post: Recursive unsolvability of a problem of Thue. (Abstract 52-11-394-t.)

38. R. C. Roberts: On the lift of a triangular wing at supersonic speeds. (Abstract 52-11-382-t.)

39. H. E. Salzer: An alternative definition of reciprocal differences. (Abstract 52-11-383-t.)

40. H. E. Salzer: Tables for facilitating the use of Chebyshev's quadrature formula. (Abstract 52-11-384-t.)

41. Alice T. Schafer: The neighborhood of an undulation point on a space curve. (Abstract 52-11-392-t.)

42. A. R. Schweitzer: Sums and products of ordered dyads in the foundations of algebra. V. (Abstract 52-11-352-t.)

43. A. R. Schweitzer: Sums and products of ordered dyads in the foundations of algebra. VI. (Abstract 52-11-353-t.)

44. I. E. Segal: The group algebra of a locally compact group. (Abstract 52-11-375-t.)

45. Fred Supnick: Cooperative phenomena. I. Structure of the linear Ising model. (Abstract 52-11-386-t.) 
46. Fred Supnick: On the problem of Tait. Preliminary report. (Abstract 52-11-407-t.)

47. J. M. Thomas: Eliminants. (Abstract 52-9-279-t.)

48. J. H. M. Wedderburn: Note on Goldbach's theorem. (Abstract 52-9-280-t.)

49. J. E. Wilkins: The converse of a theorem of Tchaplygin on differential inequalities. (Abstract 52-11-376-t.)

T. R. HOLLCROFT, Associate Secretary 